\title{
ESTUDO DA ESTABILIDADE FENOTÍPICA DE FEIJOEIRO COM GRÃOS ESPECIAIS
}

\author{
Study of the phenotypical stability of common bean plants with special grains
}

\author{
João Guilherme Ribeiro Gonçalves, ${ }^{1}$, Alisson Fernando Chiorato ${ }^{2}$, Lizz Kezzy de Morais ${ }^{4}$, \\ Eliana Francischinelli Perina ${ }^{3}$, Francine Lunardi Farias ${ }^{5}$, Sérgio Augusto Morais Carbonell ${ }^{2}$
}

\begin{abstract}
RESUMO
Obejtivou-se no presente trabalho avaliar os parâmetros de adaptabilidade e de estabilidade de linhagens e cultivares de feijoeiro, com grãos especiais, por meio do uso do genótipo suplementar (GS) em análise AMMI (Additive Main Effect and Multiplicative Interaction). Foram utilizados dados de produtividade de grãos de 14 genótipos de feijoeiro pertencentes ao ensaio de Valor de Cultivo e Uso (VCU), para o estado de São Paulo, referente às safras de 2005/2006/2007, semeados em 24 ambientes no delineamento de blocos casualizados, com três repetições. Pôde-se observar diferenças no comportamento dos genótipos em função do estímulo do ambiente, uma vez que a interação genótipo x ambiente foi significativa. Para tanto os genótipos Gen 99 TGR 34-16 (época das águas), Jalo Precoce e IAC - Centauro (época da seca), Gen 99 TG 28-68 e IAC-Centauro (época de inverno) e IAC-Boreal (conjunto das três épocas) apresentaram-se estáveis, pois seus valores de escores foram próximos de zero. Em relação ao conjunto das três épocas de semeadura não foi detectado nenhum genótipo próximo ao GS, no entanto os genótipos IAPAR-31 e IAC-Centauro (época da seca), Gen 99 TG 28-68 e IAC-Centauro (época de inverno) aproximaram-se desse ponto tendo como característica o fato de interagirem com os ambientes de maneira mais favorável possível. Sendo assim, o método AMMI combinado com o uso do GS auxilia na identificação de genótipos superiores.
\end{abstract}

Termos para indexação: Phaseolus vulgaris, interação genótipo x ambiente, adaptabilidade.

\begin{abstract}
The objective of the present study is to evaluate adaptability and stability parameters of lines and cultivars of common bean plants with special grains through the use of supplementary genotypes (GS) and AMMI (Additive Main Effect and Multiplicative Interaction) analysis. Productivity data of 14 lines and cultivars of common beans belonging to the Value for Cultivation and Use (VCU assay) of the State of São Paulo, referent to the harvests of 2005/2006/2007, seeded in twenty-four environments following a randomized blocks design with three repetitions, were used. It is possible to observe performance differences of the genotypes in function of environmental stimulus, since the genotype $x$ environment integration was significant. Genotypes Gen 99 TGR 34-16 (raining period), Jalo Precoce and IAC - Centauro (dry period), Gen 99 TG 28-68 and IAC-Centauro (winter period) and IAC Boreal (set of all the three periods) were stable, presenting score values close to zero. Regarding the set of the three seeding periods, we did not detect any genotype close to GS; nevertheless, the genotypes IAPAR-31 and IAC-Centauro (dry period), Gen99 TG 2868 and IAC-Centauro (winter period) were close to this point, interacting with environments in the most favorable way as possible. Therefore, the AMMI method combined with GS use helps to identify superior genotypes.
\end{abstract}

Index terms: Phaseolus vulgaris, genotype x environment interaction, adaptability.

(Recebido em 12 de setembro de 2008 e aprovado em 31 de maio de 2010)

\section{INTRODUÇÃO}

O Brasil destaca-se na produção e no consumo mundial de feijão (Phaseolus vulgaris L.), sendo essa leguminosa a principal fonte de proteína vegetal de consumo direto. $\mathrm{O}$ feijoeiro é uma cultura de alto valor socioeconômico e faz parte do sistema de produção de pequenos, médios e grandes produtores e de acordo com Couto et al. (2008), gera mão de obra durante todo o ciclo da cultura. De acordo com Fachini et al. (2006), além da importância do feijão na alimentação da população brasileira e mundial, a cadeia de produção, beneficiamento e comercialização, gera ocupação e renda, principalmente à classe menos privilegiada.

Os feijões com grãos especiais são originários das regiões Andinas da América Latina e apresentam uma grande diversidade de cores e seus tamanhos são normalmente o dobro do feijão carioquinha. Como procedem de localidades de clima temperado, seu cultivo no Brasil é muitas vezes inviável. Dessa forma, os programas de melhoramento genético do feijoeiro vêm buscando identificar feijões especiais que melhor se

\footnotetext{
${ }^{1}$ Instituto Agronômico/IAC - Agência Paulista de Tecnologia dos Agronegócios/APTA - Cx. P. 28-13012-970-Campinas, SP - jgrgonalves@yahoo.com.br ${ }^{2}$ Instituto Agronômico/IAC - Agência Paulista de Tecnologia dos Agronegócios/APTA - Campinas, SP

${ }^{3}$ Instituto Agronômico/IAC - Campinas, SP

${ }^{4}$ Embrapa Tabuleiros Costeiros - Campus Delta Gitaí - Rio Largo, AL

${ }^{5}$ Universidade Federal de Santa Catarina/UFSC - Florianópolis, SC
}

Ciênc. agrotec., Lavras, v. 34, n. 4, p. 922-931, jul./ago., 2010 
adaptem às condições edafoclimáticas do país (Empresa Brasileira de Pesquisa Agropecuária - Embrapa, 2007). O cultivo desses feijões vem crescendo como fonte alternativa para colocar no mercado interno um produto diferenciado e de maior valor comercial. Outra alternativa, é com relação à exportação desse tipo de feijão, uma vez que no mercado internacional o produto comercializado são os feijões de grãos graúdos (Barros 2007)

O estudo da interação de genótipos com ambientes é um fator primordial quando se trata de avaliação final de linhagens, para fins de recomendação de novas cultivares de feijoeiro para o setor produtivo. Além da constante influência do ambiente no desempenho médio das cultivares de feijoeiro a sua composição nutricional também pode variar segundo Santana et al. (2009) com o local de plantio, fatores ambientais e com a cultivar.De acordo com Duarte \& Vencovsky (1999), essa interação pode ser considerada como uma das principais dificuldades encontradas pelos melhoristas de plantas, no que se refere à seleção de indivíduos superiores, uma vez que o genótipo que se apresenta superior em um determinado ambiente pode vir a não manter essa superioridade em outros ambientes. Uma alternativa para atenuar os efeitos dessa interação é por meio da identificação de genótipos com maior estabilidade aos ambientes de cultivo, proporcionada por uma série de procedimentos estatísticos, como por exemplo, o método AMMI (Morais, 2005).

O método AMMI vem ganhando espaço com relação aos estudos de adaptabilidade e estabilidade, uma vez que permite uma análise mais detalhada da interação genótipo $\mathrm{x}$ ambiente, auxilia na seleção de genótipos mais produtivos, possibilita a observação de adaptações específicas, possui facilidade de interpretação gráfica dos resultados, entre outras vantagens (Zobel et al., 1988). Para aumentar a precisão na descoberta de genótipos superiores foi introduzido em análise AMMI o chamado genótipo suplementar (GS), sendo considerado como um controle ideal com o propósito de fazer comparações entre os genótipos avaliados (reais) com o genótipo de referência (suplementar), que são definidos com base nos critérios do melhorista (Pacheco et al., 2005).

Objetivou-se, no trabalho, realizar a avaliação fenotípica de linhagens e cultivares de feijoeiro com grãos especiais, por meio da análise AMMI com o uso do Genótipo Suplementar.

\section{MATERIAL E MÉTODOS}

Nos ensaios de VCU 2005/2006/2007, para o estado de São Paulo, foram avaliadas 11 linhagens desenvolvidas pelo Programa de Melhoramento de Feijoeiro do Instituto Agronômico-IAC (Tabela 1) e três cultivares testemunhas de feijoeiro com grãos especiais, semeados em 24 ambientes (Tabela 2) na época das águas, seca e inverno, conforme o zoneamento ecológico da cultura (Pinzan et al., 1994).

Os ensaios foram instalados conforme as normas do Ministério da Agricultura e Abastecimento e do Registro Nacional de Cultivares (Brasil 2007), para ensaios de VCU de feijoeiro. O delineamento experimental utilizado foi o de

Tabela 1 - Ensaios regionais de linhagens e cultivares de feijoeiro com grãos especiais - VCU 2005/2006/2007, no estado de São Paulo.

\begin{tabular}{lllc}
\hline \multicolumn{1}{c}{ Linhagens e Cultivares de Feijoeiro } & \multicolumn{1}{c}{ Tipo de grão } & Instituição ${ }^{\underline{1}}$ & Peso de 100 Grãos (g) \\
\hline 1- Rosinha G F $_{2}$ & Rosinha - testemunha & IAC & 23,0 \\
2- Jalo Precoce & Jalo - testemunha & EMBRAPA & 34,4 \\
3- IAPAR-31 & Pintado - testemunha & IAPAR & 23,5 \\
4- IAC-Centauro & Mulatinho & IAC & 22,2 \\
5- Gen 99 TG 8-83 & Rajado redondo & IAC & 33,9 \\
6- Gen 99 TG 28-68 & Bolinha & IAC & 34,3 \\
7- Gen 99 TG 34-50 & Jabola & IAC & 30,3 \\
8- Gen 96A14-7-3-15-3V-2 & Vermelho & IAC & 29,2 \\
9- Gen 99 TGR 34-16 & Jabola & IAC & 39,1 \\
10- IAC-Boreal & Rajado alongado & IAC & 50,5 \\
11- IAC-Harmonia & Rajado claro & IAC & 41,5 \\
12- Gen 99 TGR 31-14 & Jabola & IAC & 36,7 \\
13- Gen 99 TGR 1-10 & Branco & IAC & 30,4 \\
14- IAC-Galante & Rosinha & IAC & 28,8 \\
\hline
\end{tabular}

1/IAC= Instituto Agronômico; IAPAR= Instituto Agronômico do Paraná; EMBRAPA= Empresa Brasileira de Pesquisa Agropecuária. 
blocos casualizados, com três repetições. As parcelas foram de quatro linhas de quatro metros de comprimento, sendo as duas linhas centrais consideradas para a área útil. $\mathrm{O}$ espaçamento entre linhas foi de 0,5 metros com 10 a 12 plantas viáveis por metro linear.

Posteriormente à coleta dos dados (produtividade de grãos) foi realizada a análise de variância individual e conjunta, aceitando-se os resultados de ensaios com coeficiente de variação inferior a $25 \%$. Para fins de homogeneidade das variâncias utilizou-se o teste de Hartley $\left(\mathrm{F}_{\text {máx }}\right)$ (Ramalho et al., 2000) e, quando necessário, foram realizados ajustes nos graus de liberdade conforme Cochran (1954), citado por Pimentel-Gomes (2000).

Quando detectada interação significativa, procederam-se às análises de adaptabilidade e estabilidade por meio da análise AMMI a fim de avaliar o comportamento de cada genótipo diante às variações do ambiente. Para tanto foi realizada a seleção do modelo AMMI que melhor descreve a interação pelo teste $\mathrm{F}_{\mathrm{r}}$ de Cornelius et al. (1992), citados por Piepho (1995). De acordo com Weber et al. (1996). O propósito da análise não é recuperar toda a soma de quadrados da interação genótipo x ambiente, mas somente a parcela realmente relacionada com os genótipos e ambientes, denominada de porção padrão. A outra parcela, ou seja, a porção ruído é descartada com o intuito de melhorar a capacidade de predição do modelo (Zobel et al., 1988).

Com o objetivo de aumentar a precisão na identificação de genótipos que apresentem características agronômicas desejáveis, como estabilidade de produção e elevada produtividade nos ambientes avaliados, torna-se interessante incluir um genótipo suplementar (GS) na análise, para que se torne possível a comparação desse genótipo de referência com os genótipos reais que estão sendo avaliados. O GS é um vetor adicionado na matriz de dados originais com o intuito de identificar indivíduos interessantes. É baseado no método de Lin \& Binns (1988) e sua representação não deve influenciar a disposição de genótipos e de ambientes reais no gráfico biplot. Pode-se assumir que esse genótipo simula uma testemunha de adaptação ótima relativamente ao conjunto avaliado e, portanto, de elevada estabilidade agronômica (Pacheco et al., 2005).

A interpretação dos resultados foi realizada por meio da observação dos gráficos biplot, e os genótipos que apresentaram escores próximos de zero foram considerados estáveis e os que se mantiveram próximos do genótipo suplementar (GS) foram considerados portadores de características agronômicas desejáveis como estabilidade agronômica e elevada produtividade. Foi utilizada uma rotina computacional em linguagem SAS/IML, com adaptações ao programa disponibilizado por Duarte \& Vencovsky (1999) para a realização da análise.

\section{RESULTADOS E DISCUSSÃO}

Os efeitos da interação genótipo x ambiente, o efeito de ambiente e o efeito de genótipo foram significativos pelo teste $\mathrm{F}$, a $5 \%$ de probabilidade de erro, para todas as épocas de semeadura.

Por meio da metodologia AMMI, para a época das águas, foi possível decompor a matriz da interação em oito componentes principais (posto da matriz genótipo $\mathrm{x}$ ambiente, em que $p$ é o mínimo entre g-1 e a-1\{[min (14-1) e $(9-1)]=8\}$ ). Analisando a Tabela 3 , pode-se observar que os quatro primeiros eixos são significativos $(\mathrm{p}<0,001)$, levando à seleção do modelo AMMI4 segundo o critério do teste de $\mathrm{F}_{\mathrm{r}}$ de Cornelius et al. (1992). Entretanto, os gráficos foram elaborados utilizando-se os três primeiros eixos conforme Carbonell et al. (2004), devido à facilidade de interpretação gráfica. No entanto poderia ser interpretado em modelos superiores a três eixos, pelas tabelas de médias preditas e estimativas da interação genótipo $\mathrm{x}$ ambiente. Esses três primeiros eixos acumularam $83,41 \%$ da $\mathrm{SQ}_{\mathrm{G} \times \mathrm{A}}$, porção denominada padrão e o restante da $\mathrm{SQ}_{\mathrm{Gx}}$, ou seja, 16,59\% correspondente à porção ruído.

Tabela 2 - Ambientes utilizados para a condução dos ensaios nas respectivas épocas de semeadura.

\begin{tabular}{|c|c|c|c|c|c|}
\hline \multicolumn{6}{|c|}{ Épocas de semeadura } \\
\hline Águas/2005 & Águas/2006 & Seca/2006 & Seca/2007 & Inverno/2006 & Inverno/2007 \\
\hline A- Capão Bonito & E- Holambra II & J- Mococa & O- Avaré & R- Fernandópolis & V- Mococa \\
\hline $\begin{array}{l}\text { B- Monte Alegre } \\
\text { do Sul }\end{array}$ & F- Avaré & K- Avaré & P- Tatuí & S- Ribeirão Preto & $\mathrm{X}$ - Araras \\
\hline C- Tatuí & G- Mococa & $\begin{array}{l}\text { L- Espírito Santo } \\
\text { do Pinhal }\end{array}$ & $\begin{array}{l}\text { Q- Monte } \\
\text { Alegre do Sul }\end{array}$ & $\mathrm{T}$ - Votuporanga & Z- Colina \\
\hline D- Mococa & $\begin{array}{l}\text { H- Capão Bonito } \\
\text { I- Itaberá }\end{array}$ & $\begin{array}{l}\text { M- Tatuí } \\
\text { N- Capão Bonito }\end{array}$ & & U- Colina & \\
\hline
\end{tabular}

Ciênc. agrotec., Lavras, v. 34, n. 4, p. 922-931, jul./ago., 2010 


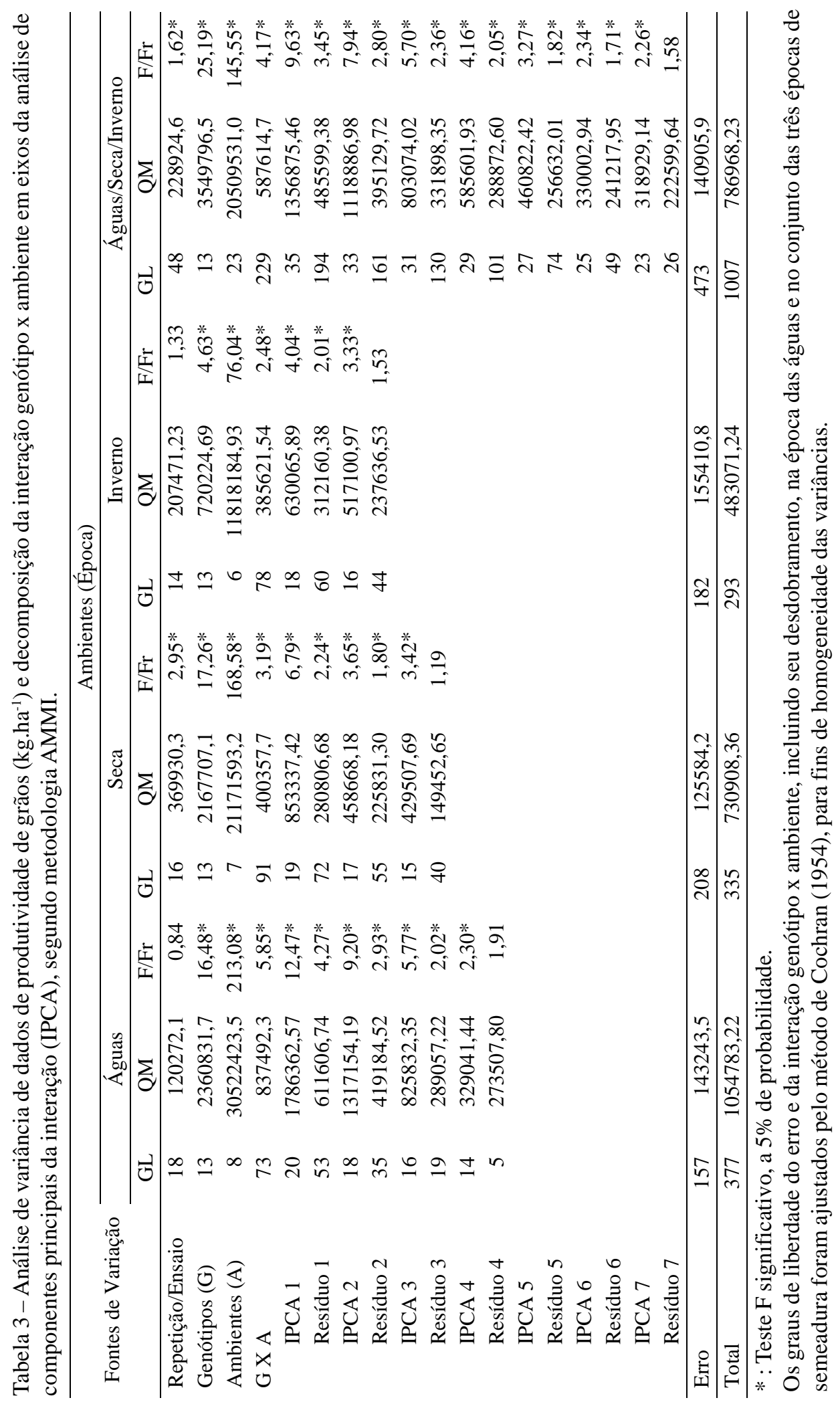


Pode-se constatar por meio das Figuras 1 e 2 que o genótipo Gen 99 TGR 34-16 (9) foi o que mais se aproximou do eixo central uma vez que apresentou baixos valores de escores, sendo assim considerado estável e também se destaca por possuir produtividade acima da média, quando comparado com os demais genótipos. No entanto, os genótipos Jalo
Precoce (2), IAC-Galante (14) e Gen 96A14-7-3-15-3V-2 (8) obtiveram os maiores valores de escores, ou seja, foram os que mais contribuíram com a interação genótipo x ambiente. Também pode-se observar que não houve genótipos próximos do GS, que simula uma testemunha de ótima adaptação em ambos os ambientes avaliados.

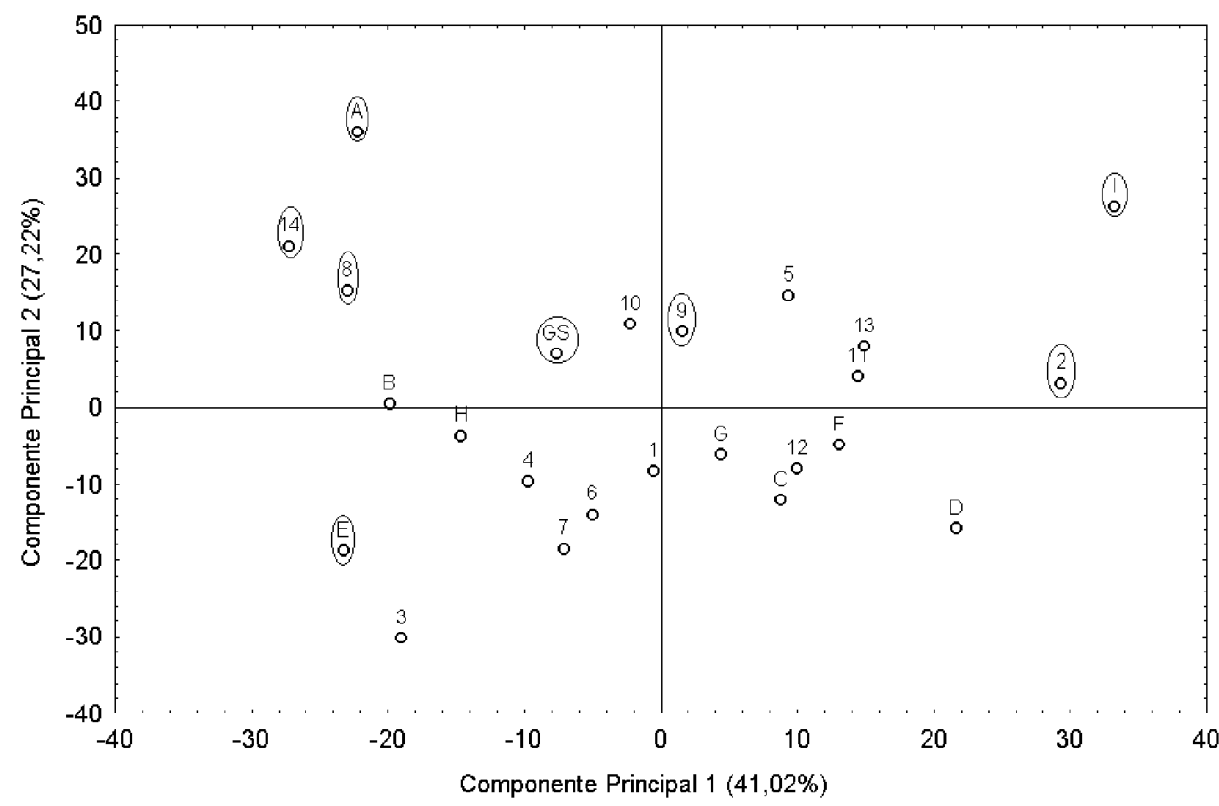

Figura 1 - Gráfico biplot de modelo AMMI3, referente à época das águas.

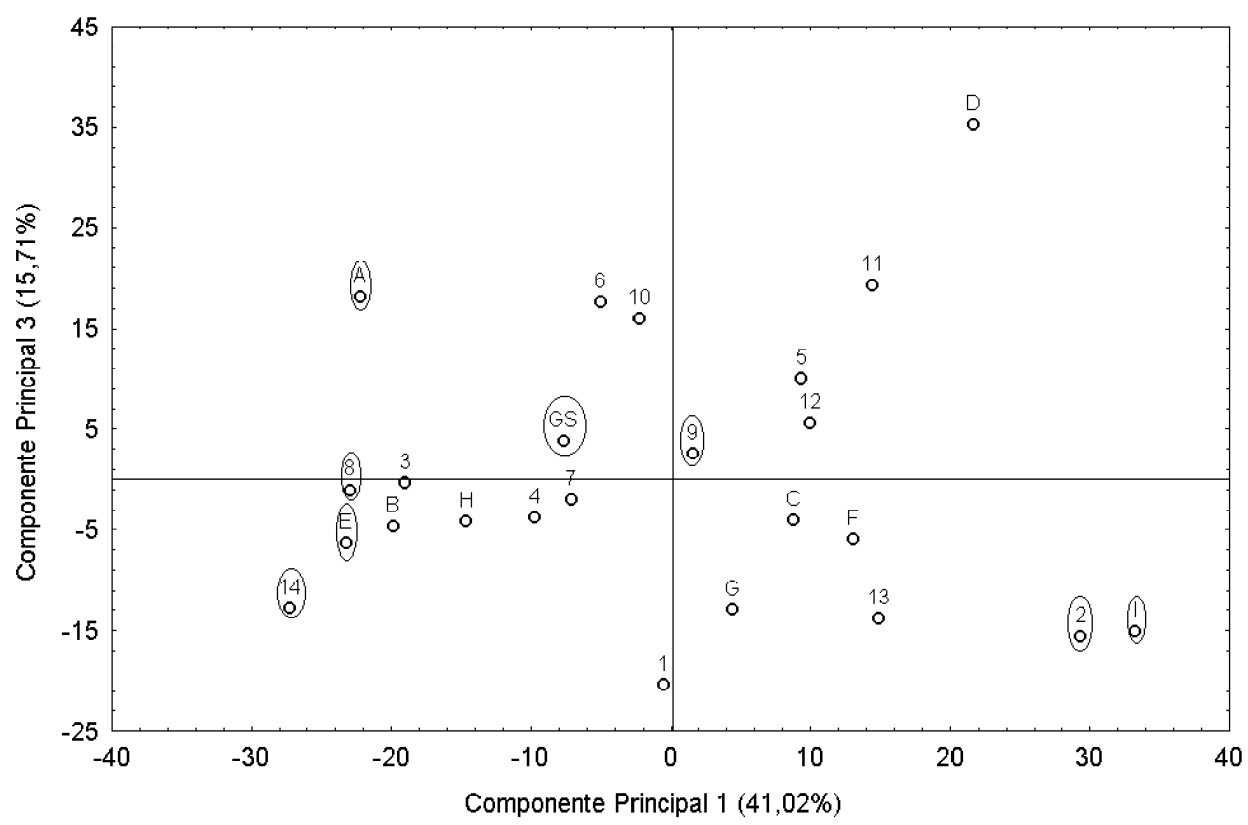

Figura 2 - Gráfico biplot de modelo AMMI3, referente à época das águas. 
Devido às diferenças edafoclimáticas bem como da maior propensão de ocorrência de pragas e doenças em determinados ambientes, pode-se observar algumas adaptações específicas de genótipos a determinados ambientes pela análise AMMI (Figura 1 e 2). Como exemplo, a cultivar Jalo Precoce (2) e a linhagem Gen 99 TGR 1-10 (13), adaptados ao ambiente de Itaberá (I), o genótipo IACBoreal (10), ao ambiente de Capão Bonito (A) e os genótipos IAC-Centauro (4), Gen 99 TG 34-50 (7), IAPAR-31 (3) e Rosinha $\mathrm{G}_{2}(1)$, adaptados especificamente aos ambientes de Capão Bonito (H) e Holambra II (E). Os ambientes que mais contribuíram com a interação foram os de Itaberá (I), Capão Bonito (A) e Holambra II (E). De uma maneira geral, os ambientes ficaram distribuídos pelo gráfico (Figuras $1 \mathrm{e}$ 2), mostrando o quanto são diferentes em questões de solo e clima.

Em relação à época da seca, os três primeiros eixos foram significativos levando à seleção do modelo AMMI3 (Tabela 3), podendo observar por meio das Figuras 3 e 4 que os genótipos Jalo Precoce (2) e IAC - Centauro (4) foram os que mais se aproximaram do eixo central, sendo considerados estáveis. Já os genótipos Gen 99 TG 28-68 (6) e Gen 99 TGR 34-16 (9) foram os mais instáveis, ou seja, os que mais contribuíram com a interação, pois apresentaram maiores valores de escores. Pode-se também constatar que as cultivares IAPAR-31 (3) e IAC-
Centauro (4) apresentaram-se produtivas e com estabilidade agronômica, uma vez que localizaram-se próximas ao GS.

É importante considerar, que de uma forma geral, os ambientes ficaram bastante distribuídos pelo gráfico (Figuras 3 e 4), indicando o quanto são divergentes em condições de solo e clima.

Pelas mesmas condições citadas para a época das águas, pode-se observar que o genótipo Gen 99 TG 28-68 (6) adaptou-se especificamente ao ambiente de Monte Alegre do Sul (Q); os genótipos Gen 96A14-7-3-15-3V-2 (8) e Jalo Precoce (2), ao ambiente de Tatuí (M) e os genótipos IAC-Boreal (10), IAC-Centauro (4) e IAPAR-31 (3), adaptados ao ambiente de Avaré $(\mathrm{O})$.

Para a época de inverno foi selecionado o modelo AMMI2 (Tabela 3). De acordo com a Figura 5 pode-se observar que os genótipos que mais contribuíram com a interação genótipo x ambiente, ou seja, os que obtiveram os maiores valores de escores foram os genótipos Rosinha $\mathrm{G}_{2}$ (1), IAC-Galante (14) e Jalo Precoce (2). Os genótipos Gen 99 TG 28-68 (6) e IAC-Centauro (4) foram os que mais se aproximaram de zero na formação do gráfico biplot, apresentando-se estáveis. Esses genótipos também se mantiveram próximos ao GS por apresentarem características desejáveis, como estabiliadade agronômica e alta produtividade.

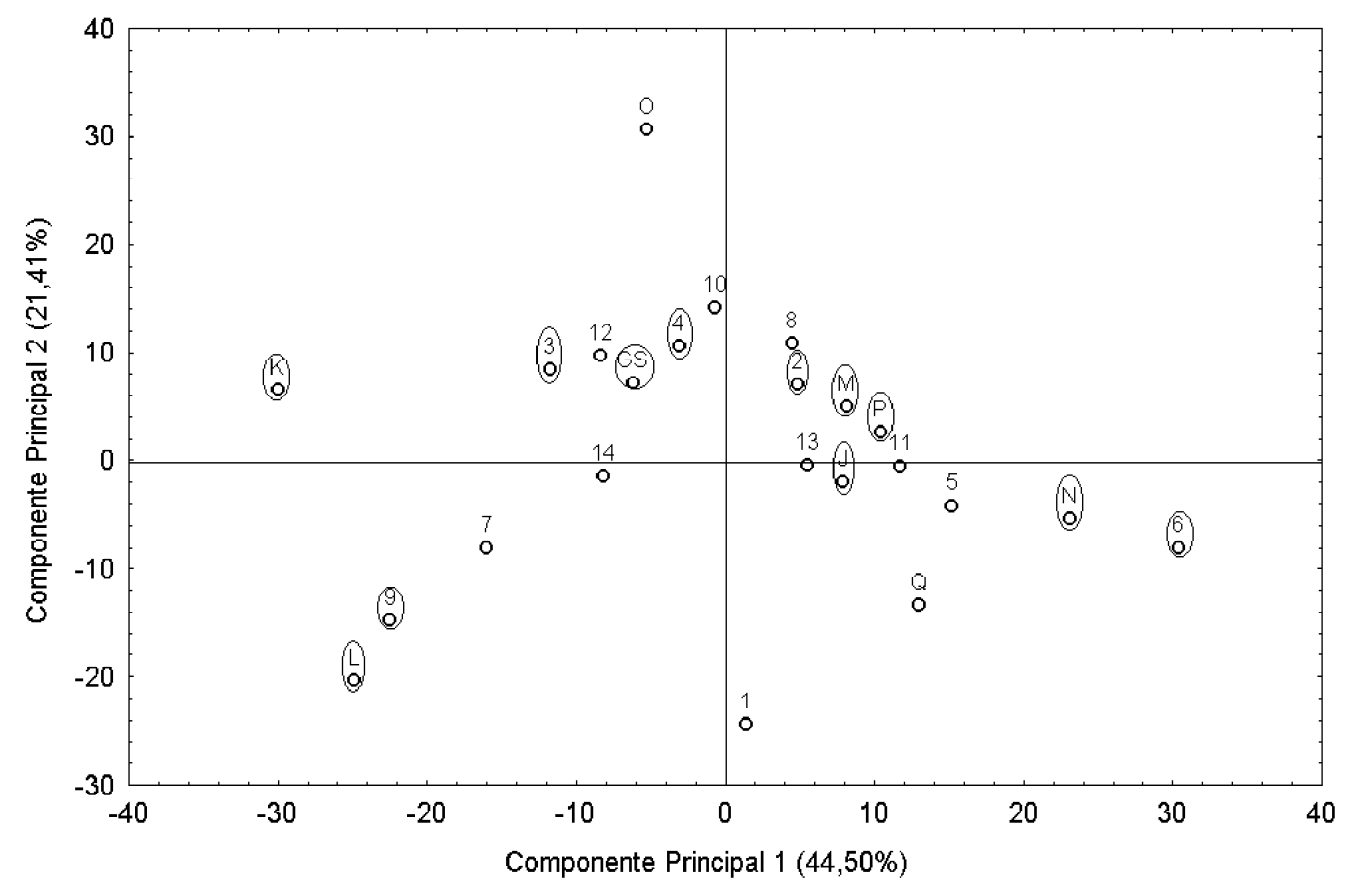

Figura 3 - Gráfico biplot de modelo AMMI3, referente à época da seca. 


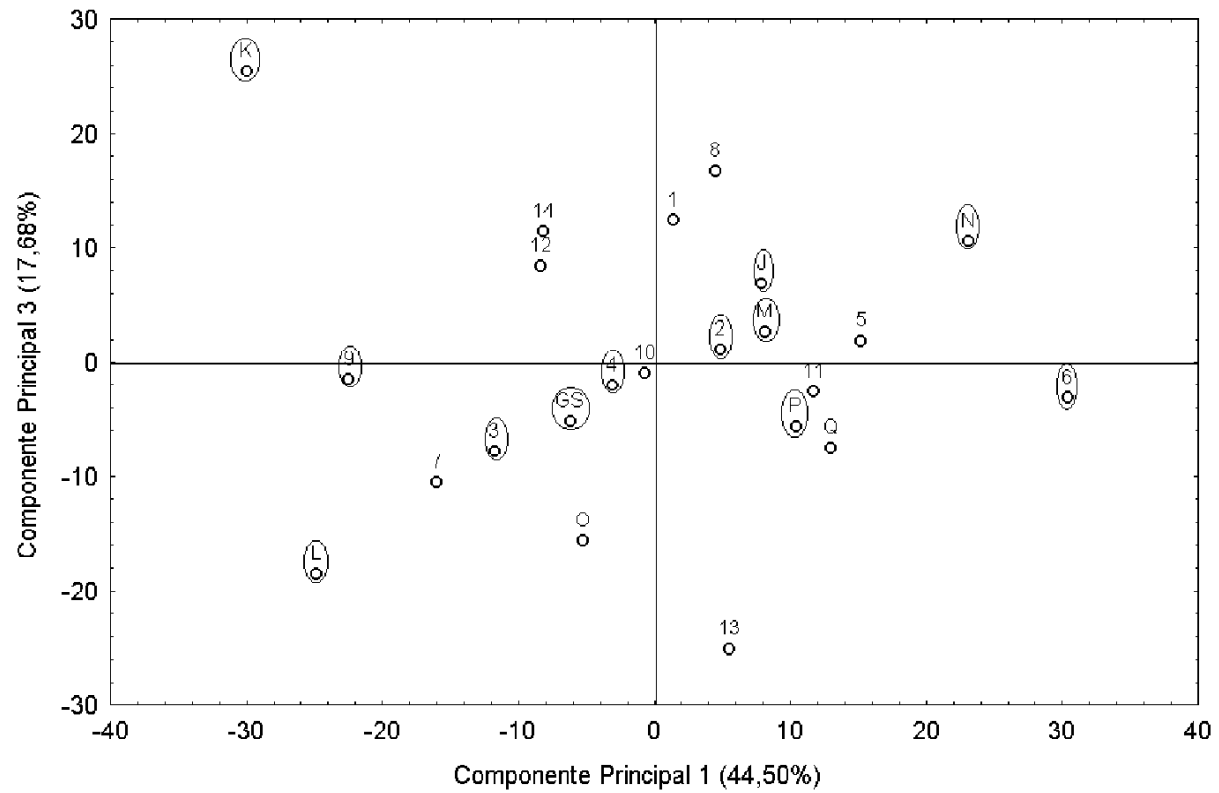

Figura 4 - Gráfico biplot de modelo AMMI3, referente à época da seca.

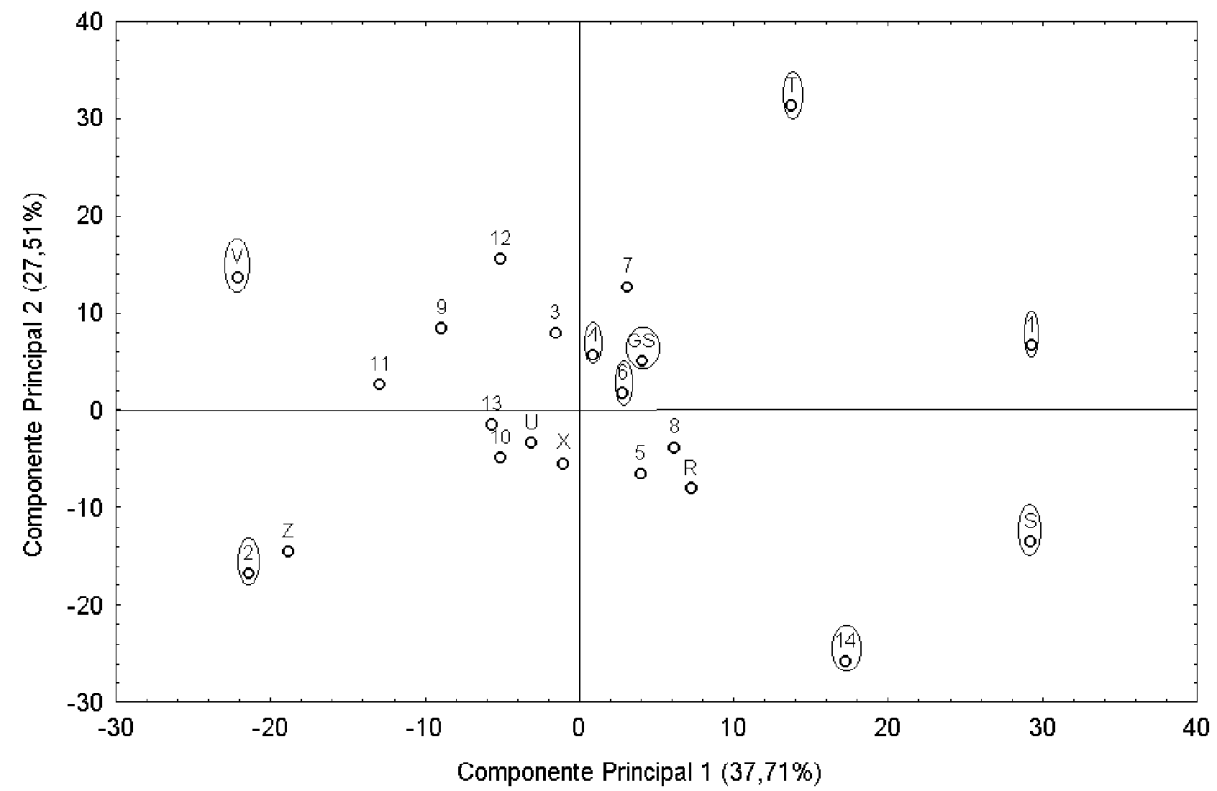

Figura 5 - Gráfico biplot de modelo AMMI2, referente à época de inverno.

Os ambientes que mais contribuíram com a interação foram Ribeirão Preto (S), Votuporanga (T) e Mococa (V), uma vez que apresentaram os maiores valores de escores. Pode-se ainda observar algumas adaptações específicas, como por exemplo, os genótipos Gen 96A14-7-3-15-3V-2 (8) e Gen 99 TG 8-83 (5), ao ambiente de Fernandópolis (R) e o genótipo IACBoreal (10), adaptado aos ambientes de Colina (U) e Araras (X).
Quanto ao conjunto das três épocas de semeadura, os sete primeiros eixos foram significativos $(\mathrm{p}<0,001)$, levando à seleção do modelo AMMI7 (Tabela 3), segundo o teste $\mathrm{F}_{\mathrm{r}}$ de Cornelius et al. (1992), entretanto os gráficos foram elaborados utilizando-se somente os três primeiros eixos devido às mesmas considerações mencionadas para a época das águas. 
O genótipo IAC-Boreal (10) foi o mais estável enquanto que os genótipos IAC-Galante (14) e Jalo Precoce (2) foram os que mais contribuíram com a interação (Figura 6 e 7). Já os ambientes que proporcionaram maior estabilidade de produção de grãos para as linhagens avaliadas foram: Mococa (J), Tatuí (M), Fernandópolis (R), Monte Alegre do
Sul (Q), Tatuí (P), Capão Bonito (N) e Avaré (O). Pode-se também observar que nenhum genótipo se aproximou do GS ou controle ideal, indicando a necessidade de novos estudos para com esses tipos de grãos.

Pode-se também observar que os genótipos IACBoreal (10) e IAC-Harmonia (11) adaptaram-se

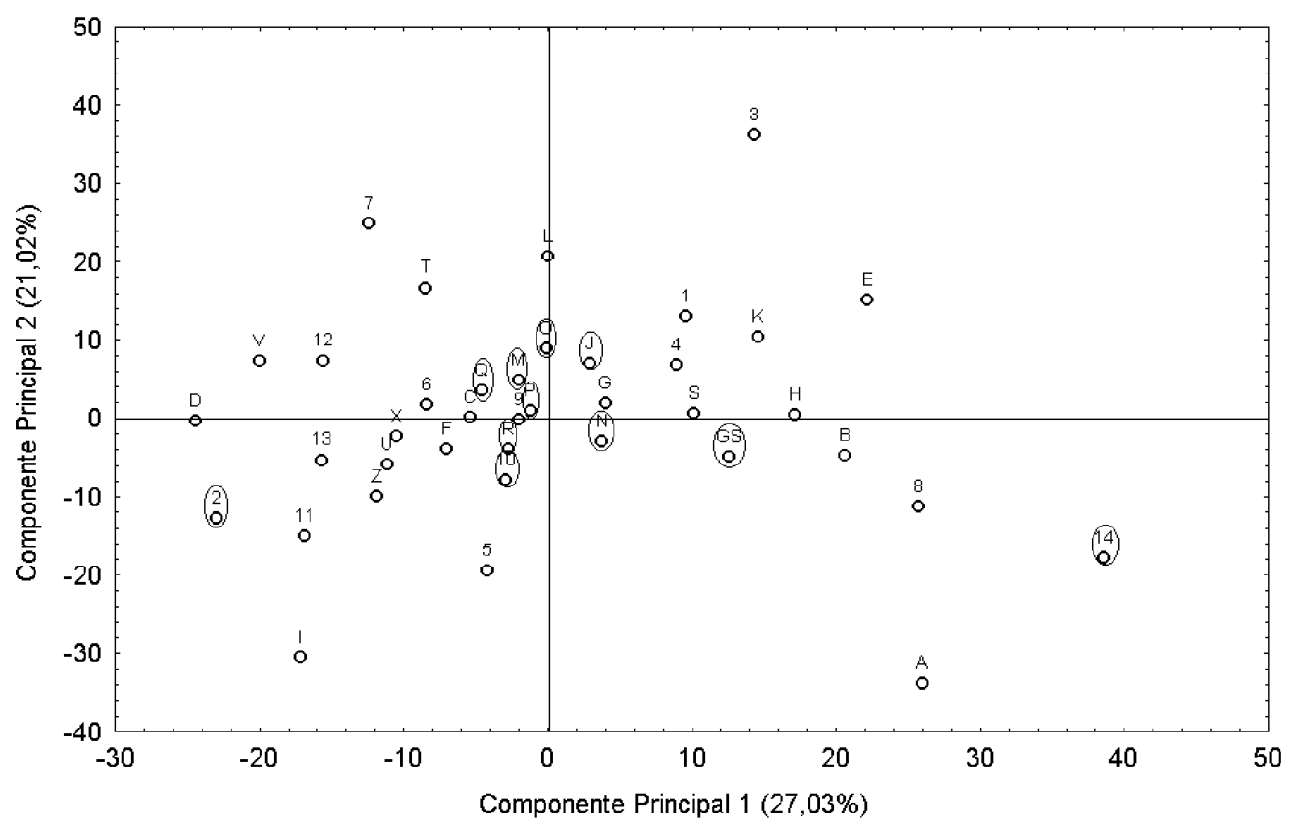

Figura 6 - Gráfico de modelo AMMI3, referente ao conjunto das três épocas de semeadura.

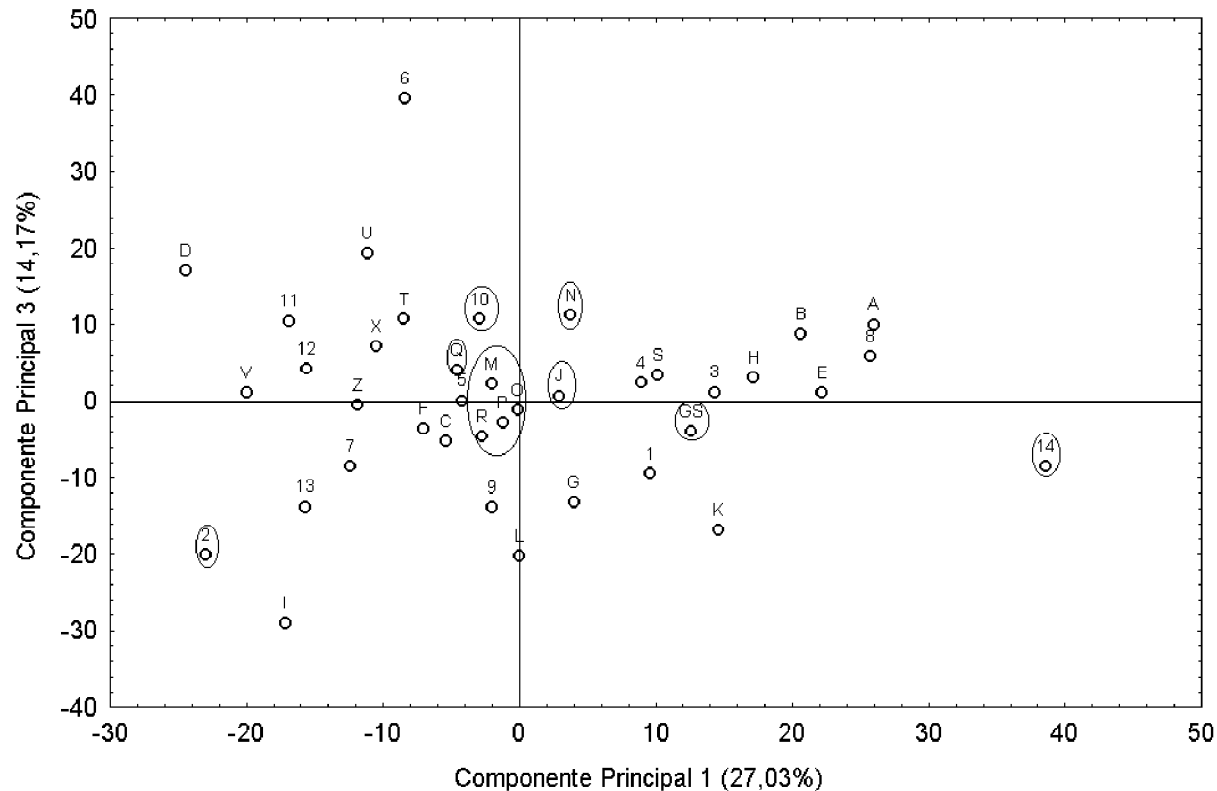

Figura 7 - Gráfico de modelo AMMI3, referente ao conjunto das três épocas de semeadura. 
especificamente aos ambientes de Colina (U), Colina (Z) e Araras (X). Vale ressaltar que esses genótipos melhor se desenvolvem, quando semeados em condições de temperaturas elevadas (características dos ambientes citados), alcançando dessa forma maiores níveis de produtividade.

É importante considerar que o desenvolvimento de cultivares de feijoeiro com grãos especiais vem ganhando espaço em vários programas de melhoramento como garantia de oferecer aos produtores uma nova alternativa de renda por meio de produtos que atendam aos nichos de mercado. O programa de melhoramento de feijoeiro do IAC lançou algumas das linhagens citadas no presente trabalho, inclusive a cultivar IAC - Boreal que apresentou estabilidade de produção com relação ao conjunto das três épocas de semeadura.

\section{CONCLUSÕES}

A inclusão do Genótipo Suplementar em análise AMMI auxilia na identificação de materiais genéticos superiores no conjunto de dados avaliados, devido à facilidade de interpretação gráfica.

A cultivar IAC - Boreal destacou-se das demais devido à estabilidade demonstrada nos 24 ambientes avaliados.

As linhagens Gen TG 28-68 e IAC-Centauro apresentaram-se próximas ao genótipo suplementar, indicando dessa forma um desempenho agronômico satisfatório nos ensaios de VCU.

\section{AGRADECIMENTOS}

Ao professor João Batista Duarte pelo auxílio com a análise, aos Pólos Regionais de Desenvolvimento Científico e Tecnológico onde foram instalados os ensaios de VCU, à CAPES, pela concessão da bolsa de estudos e a FAPESP e ao CNPq, pelo apoio financeiro.

\section{REFÊNCIAS BIBLIOGRÁFICAS}

BARROS, R.P. Feijões especiais para a agricultura familiar. Disponível em: <http:// 'www.zoonews.com.br/noticiax.php?idnoticia=221>y. Acesso em: 17 maio 2007.

BRASIL. Ministério da Agricultura, Pecuária e Abastecimento. Registro Nacional de Cultivares. Requisitos mínimos para determinação do valor de cultivo e uso de feijão (Phaseolus vulgaris) para a inscrição no registro nacional de cultivares, RNC. Brasília, 2007.
CARBONELL, S.A.M.; AZEVEDO FILHO, J.A.A.; DIAS, L.A.S.; GARCIA, A.A.F.; MORAIS, L.K. Common bean cultivars and lines interaction with environments. Scientia Agricola, Piracicaba, v.61, n.2, p.169-177, 2004.

COUTO, M. A.; SANTOS, J. B. dos; FERREIRA, J. L. Melhoramento do feijoeiro comum com grão tipo carioca, visando resistência à antracnose e à mancha angular. Ciência e Agrotecnologia, Lavras, v.32, n.5, p. 1643-1648, set./out., 2008.

DUARTE, J.B.; VENCOVSKY, R. Interação genótipos x ambientes: uma introdução a análise AMMI. Ribeirão Preto: Sociedade Brasileira de Genética, 1999. 60p.

EMPRESA BRASILEIRA DE PESQUISA

AGROPECUÁRIA. Arroz e feijão integram mostra tecnológica da Embrapa. Disponível em: <http:// iwWw.cnpaf.embrapa.br/<eventosenoticias/anteriores anteriores2006/060313.htm>. Acesso em: 6 jun. $2007 \mathrm{a}$.

FACHINI, C.; BARROS, V.L.N.P.; RAMOS JUNIOR, E.U.; ITO, M.A.; CASTRO, J.L. Importância do feijão no agronegócio brasileiro. In: DIA DE CAMPO DE FEIJÃO, 78., 2006, Capão Bonito. Resumos... Capão Bonito: IAC, 2006. p.1-7. (Documentos IAC).

LIN, C.S.; BINNS, M.R. A superiority measure of cultivar performance for cultivar x location data. Canadian Journal of Plant Science, Ottawa, v.68, n.1, p.193-198, 1988.

MORAIS, L.K. Adaptabilidade e estabilidade fenotípica em soja nos Estados de Mato Grosso e Mato Grosso do Sul. 2005. 98p. Tese (Doutorado em Agronomia)Universidade Federal de Goiás, Goiânia, 2005.

PACHECO, R.M.; DUARTE, J.B.; VENCOVSKY, R.; PINHEIRO, J.B.; OLIVEIRA, A.B. Use of supplementary genotypes in AMMI analysis. Theoretical and Applied Genetics, Berlin, p.812-818, 2005.

PIEPHO, H.P. Robustness of statistical test for multiplicative terms in the additive main effects and multiplicative interaction model for cultivar trial.

Theoretical Applied of Genetics, Berlin, v.90, p.438-443, 1995.

PIMENTEL-GOMES, F. Curso de estatística experimental. Piracicaba: Nobel, 2000. 477p. 
PINZAN, N.R.; BULISANI, E.A.; BERTI, A.J. Feijão: zoneamento ecológico e épocas de semeadura para o estado de São Paulo. Campinas: CATI, 1994. 19p.

(Boletim técnico CATI, 218).

RAMALHO, M.A.P.; FERREIRA, D.F.; OLIVEIRA, A.C. Experimentação em genética e melhoramento de plantas. Lavras: UFLA, 2000. 326p.

SANTANA, M .J. de; CARVALHO, J. de A.; ANDRADE, M. J. B. de; GERVÁSIO, G. G.; BRAGA, J. C.; LEPRI, E. B. Variabilidade técnica e econômica da aplicação de água na cultura do feijoeiro comum (Phaseolus vulgaris L.).
Ciência e Agrotecnologia, Lavras, v.33, n.2, p. 532-538, mar./abr., 2009.

WEBER, W.E.; WRICKE, G.; WESTERMANN, T. Selection of genotypes and prediction of performance by analyzing genotype-environment interactions. In: KANG, M.S.; GAUCH JUNIOR, H.G. (Eds.). Genotype by environment interaction. Boca Raton: CRC, 1996. p.353371.

ZOBEL, R.W.; WRIGHT, M.J.; GAUCH, H.G. Statistical analysis of a yield trial. Agronomy Journal, Madison, v.80, n.3, p.388-393, 1988 . 